\title{
The Arts and the Authentic Learner
}

\section{ZUZANA VASKO}

Simon Fraser University

\begin{abstract}
Amidst a goal-oriented society driven by a market economy, knowing one's truer values and finding a sense of personal authenticity may seem challenging. With the view that education is to prepare a student for a meaningful life, this paper looks toward how arts education and the encouragement of aesthetic experience can go a long way toward belping students find a sense of authenticity in their lives. The arts foster a connection with the self as well as with our peers and the culture of which we are a part. The humanizing characteristics of art such as the emotions, intuition, our bodies and senses, and our beliefs are explored, as is the role of contemporary art. While this paper takes the viewpoint of a visual artist, the ideas apply to the arts in general.
\end{abstract}

With the effects of globalization, the media, and goal-oriented thinking coming at us from so many directions, it is at times challenging to know what is truly valuable for ourselves as human beings, and to find authenticity in our own lives. The effects of the market economy find their way into our consciousness from a myriad of angles. They have the capacity, if not to dim the colours of some of our most valued sympathies, then to blunt our own connection with them. When the greater culture, largely driven by advancement and profit, reflects itself boldly in so many places, it can at times be difficult to truly know where our values and closest affiliations lie. The social and aesthetic influences of the market media, especially on young people, are considerable. They play upon individual identities - our sense of who we are in this world, and our place in it. Yet most of all, there are the effects that a consumerist, technocratic, and goal-oriented society can have on the very rhythms of our everyday life. We are encouraged to fill our schedules beyond capacity, to do things perfunctorily rather than to get absorbed for the sake of depth or engagement, and to measure success by results rather than by the meaning of the experience.

Charles Taylor describes this instrumentalist tendency as stemming from "the kind of rationality we draw on when we calculate the most economical application of means to a given end."1 Instrumental thinking has become more normal to us than we perhaps realize. As Terry Eagleton observes, it has become increasingly difficult in recent times to think in non-instrumental terms - so pervasive is this model of thinking that it has also infected our moral decision-making. Modern capitalist societies, he points out, are often preoccupied with the most efficient means to an end, and consequently, our ideas of how to live well are also often seen as "a matter of acting so as to attain a certain goal." 2 In our everyday lives, instrumentalism has the capacity to take us away from getting truly absorbed in something purely for its own sake, and from being guided by the fulfilment an experience itself may have to offer. I believe that this not only impoverishes our lives, it depletes our humanness. Our very sense of time, and of our presence in this world is manipulated, and diminished. While it is beneficial, and often necessary, to have goals in life, and while the challenge of working toward something specific often proves satisfying and fruitful in the end,

1 Taylor, C. The Malaise of Modernity (Toronto: House of Anansi Press, 2003) p. 5.

${ }^{2}$ Eagleton, T. After Theory (London: Penguin, 2003) p. 123.

(C) Copyright 2007. The author, Zurana Vasko, assigns to the SFU Educational Review the right of first publication and educational and non-profit institutions a non-exclusive license to use this document for personal use and in courses of instruction provided that the article is used in full and this copyright statement is reproduced. Any other usage is probibited without the express permission of the author. 
many goals become less meaningful if attentiveness is not brought to the actual process of getting there. A mode of thinking interested primarily in pragmatics and results takes us away from ourselves in that it eludes, in many ways, what is felt and sensed within. The nature of our desire, one of the very things that makes us human, is moulded and redirected to achieve ends that in themselves are often not as fulfilling as we may have hoped. As Stuart Richmond points out, to do something for its own sake in today's society is a kind of subversive act. ${ }^{3}$ We need time, as he says, to lie fallow for a while - to disconnect from the world and reconnect with ourselves, find peace and solitude, develop an authentic self, and have a life of our own.

According to the research of Mihaly Csikszentmihalyi, many North Americans tend to spend the bulk of their time either in the driven anxiety of their jobs, or escaping from that anxiety in a kind of passive boredom or hedonism, with little true engagement in activities that are personally meaningful to them. ${ }^{4}$ If we are to think of education as preparing a student for life, not just for the job market, then the very pertinent question of what makes an individual life meaningful and fulfilling needs to be asked. Viewed this way, education can become the place to initiate students into practices that they deem worthwhile and significant. It can also become the place to instil the idea of a kind of intuitive self-guidance, a way of spending time, and engaging with the world.

Eagleton reminds us that "the point about human nature is that it does not have a goal," and that if we are to have a semblance of well-being in our lives, and to be, as he says, what it is in us to be, then we must be allowed to do what we do just for the sake of it. ${ }^{5}$ Aesthetic experience brings us back, in so many ways, to simply being. We become lost, absorbed in what is before and around us, connected to it through our senses and our bodies. Being attentive aesthetically helps us to realize an intrinsic way of being, as Richmond says. It is a state of appreciating and perceiving, of taking things in without commensurable judgement. We are engaged intellectually as well as emotionally, and thereby find a means to connect with ourselves, our surroundings, and others.

It is my sense that occasions are needed which encourage the exploration of ways of working, of knowing, and of being that are more intuitive, and that call on the imagination to better help us understand our lives and the lives of others. These occasions create a place of safety where students can look within themselves and take the risk to express sincerely what they find there. It is also a place where they can respond directly, even spontaneously, to their social and material surroundings. My aim in this paper is to call attention to some of the powerful ways in which the arts can engender a sense of authenticity. The arts provide many of the elements that are important to us as human beings, but that may often be put aside in the rush of our everyday lives. Through the arts we gain a sense of embodiment, we examine our beliefs as well as our sense of morality, we foster a connection with the self as well as with our culture as a whole, and perhaps most importantly, we address human emotion and gain a kind of understanding not often found elsewhere.

Imagine for a moment a child who becomes fascinated by the way colours of paint mix with one another, trying things out just to see what will happen. He is guided intuitively by his senses to make something of his own. Specifically, this child is engaged with a state of mind, and in a way of being, one that ideally we all have a right to, even far beyond childhood. It is precisely this state of absorption that is so difficult to describe - when the mind is figuring things out as the work goes along, guided by something that cannot actually be called thinking because it involves one's whole self. While there may be an end in sight during the process of making a piece of art, practicing a piece of music, or playing out a dramatic scene, that end is not exactly defined. Often the outcome involves an element of surprise, and is arrived at through a kind of transformation. While a satisfying result is indeed desirable, the means are very much inherent in the end and what imbue the work with its human qualities. It is the means, ultimately, that make it meaningful.

The arts bring us back to ourselves through what is sensed and felt, both tangibly and intuitively. In visual art, for example, the very process of seeing, absorbing and eventually interpreting an object or entity through artistic media connects us to it, whether it is a human being, a cluster of trees, or a built environment. A particular scene becomes more familiar, more intimately known, when it is drawn, painted or interpreted

\footnotetext{
${ }^{3}$ Dr. Stuart Richmond (S.F.U.) was my co-presenter on this topic at Education With/Out Borders.

${ }^{4}$ Csikszentmihalyi, M. Finding Flow: The Psychology of Engagement with Everyday Life (New York: Harper Collins, 1997).

${ }^{5}$ Eagleton, p. 115.
} 
through other means. Our connection with it is thereby enriched. This is even more true when the subject is another person, or one's own face in the case of a self-portrait. It is a perceptual acquaintance that involves more than just the physical. An affective quality underlies the act of observing and interpreting, as the artist's feelings and thoughts inevitably come into play. What is involved is accessing another kind of knowledge and understanding, and a different part of the mind is drawn upon from that used in the routine of the everyday. A child who responds through art to something in his or her own world, taking in and interpreting something in the surroundings, both social and physical, becomes a part of that world and develops a deeper connection with it. It is in this way that the arts can build an awareness of humanity, the physical world and one's community. In the case of non-representational work, an art student is still connecting to something - to inner thoughts and sensations that are interpreted through a vocabulary of their own by means of various forms and media.

When we are absorbed in something for it's own sake, time often seems to slip away, and our relationship with time becomes more fluid. It is not only time that seems to fall away - the self also begins to let go. A kind of paradox is involved here: through the experience of releasing part of the conscious self, we are able to come closer to ourselves. This nature of aesthetic engagement can be seen as akin to the spiritual. Additionally, many thinkers have made the connection between aesthetic experience and morality - by sensing and absorbing through the body, our intuitions and imagination allow us to grasp other realities and points of view. This is true in the case of tangible practice as well as in the act of perceiving the work of others. Iris Murdoch esteems engagement with art as one of the best forms of moral practice, since it is specifically an encounter where the self is put aside in order to reverberate with another, perhaps truer, reality. ${ }^{6}$ In a similar vein, Kant proposed that disinterestedness - by which he meant viewing an entity for its own sake and without self-interest - is what most characterizes aesthetic experience. ${ }^{7}$ The act of letting the self fall away while becoming engrossed in a work which may have a beauty, a complexity, or a truth of its own, in turn deepens our connection with what is within, as well as with something that is greater than ourselves.

The implications for imagination and human understanding through the arts are considerable. Through arts education, children and youth can find meaning in the world around them, and in their own place within that world. Arts education also provides a means to bring forth students' natural aesthetic inclinations - those that have developed through their childhood and through their heritage and upbringing. A way is provided to work with and explore their personal culture, while engaging in dialogue with the greater culture in which they find themselves. In this manner, student-teacher relationships can, and often need to, take on a personal and affective quality. That is, as a teacher finds a way to develop a student's artistic skills and knowledge, he or she also needs to be aware of each student's individual aesthetic sense, and to encourage it. While the teacher is mindful not to present herself as an absolute authority in the discipline, her role is still a powerful one.

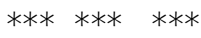

I'd like to touch upon a few of the conflicts here related to the world of contemporary visual art and the double-sided role it can play within art education and in nurturing the authentic learner. The postmodern era has brought about tremendous changes in the past decades, and it is indeed important for teachers to be aware of what is current. The practice of art has broadened to include conceptual art, performance, installation, video as well as unlimited forms of mixed media. In many ways, these developments have been freeing and expansive, and also democratizing. There is a great deal today that can be called art. In many circles, traditional skills and media, or the idea of proficiency with a medium, are no longer taken seriously. These contemporary areas of art are often seen as requiring more effort on the part of the viewer, since often

${ }^{6}$ Murdoch, I. The Sovereignty of Good (London: Routledge and Kegan Paul, 1971).

${ }^{7}$ Kant, I. The Critique of Judgement, J.C. Meridith, trans. (Oxford: Clarendon Press, 1982). Particularly helpful to me in understanding Kant's work on aesthetic experience were: Cohen, T \& Guyer, P. "Introduction," in Essays in Kant's Aesthetics, Cohen, T \& Guyer, P, eds. (Chicago: University of Chicago Press, 1982); and Richmond, S. "Remembering Beauty: Reflections on Kant and Cartier-Bresson for Aspiring Photographers" Journal of Aesthetic Education, Vol. 38 (1) pp. 78-88, 2004. 
the work is not solely, if at all, about beauty or good rendering. Its intention may be to cause us to re-examine our assumptions about society and culture, as well as about art itself and our modes of perception. A significant shift has also been toward the discourse around art, toward the conceptual and the verbal, with considerable emphasis taken away from the physical form of the work itself, and the sensuous and emotive ways of experiencing it. All of these movements have led to a wider understanding of the world of visual culture, and these certainly need to be included in any art curriculum, especially at the higher levels. It is my opinion, however, that we lose a great deal of the experience if the sensuous aspects of art, the bodily experience of perceiving and of acquiring skills, are diminished in order to favour the verbal and the conceptual. I believe that the fundamentals of art offer greater access to that part of artistic practice and understanding which encourages personal authenticity, than does the pursuit of what is current, or the honing of one's critical skills.

Matisse once wrote that he dreamed of an art characterized by balance and serenity, which might act "like a mental soother, something like a good armchair in which to rest from physical fatigue." 8 Art is certainly meant to be pleasurable, and at times to provide us with a much-needed sense of balance and serenity. Many, however, would rightly argue that the role of art extends beyond the sensuous, and that it has a role of social critique to play. It is true that issues and concepts need to be addressed and brought into art education, whether students are viewing a work or involved in the making of their own. Developing a familiarity, even a fluency, around the language of art and art criticism is also important. Yet these considerations are not, I feel, the means, or the meaning, behind art practice or appreciation. I think Kant offers a rather helpful way of viewing the balance between individual sensuous experience and the need for concepts with his idea that while we often require concepts translated into verbal form to share our experiences with others, the spontaneous feeling and imaginative free-play we experience in response to a work are what give aesthetic experience its most special qualities. ${ }^{9}$

In the last few decades, much art has focused on crossing borders, and often breaking them down altogether. Departing from traditions toward new means of expression and new fields of practice has indeed been very liberating. Art has always, in fact, been about inhabiting uncommon viewpoints, extending them, and expanding horizons. In education, however, especially if one is working with children, it is nonetheless important to remain connected with what I believe is at the core of art, and that is exploring what is most human in an individual, which may sometimes involve returning to basic and oft-revisited themes. While the arts have pushed into new areas with great avail, I feel that their most significant value is in the spheres they open up within us. It is here that they are particularly meaningful in education.

$* * * * * * \quad * * *$

The experience of working with tangible materials - paint, pastel, clay or other media - and coming to know how these materials behave is a way of engaging with the world through the senses and our physical selves, which can be a pathway toward our authentic selves. Learning, by means of practice and application, how one can use the materials creatively within their own as well as the artist's constraints is a method of connecting with the self while becoming aware of individual strengths and limitations. Finding one's way amidst various challenges, while maintaining the integrity of one's intent, vague as it may sometimes be, is a form of emancipation.

The arts cause us to inhabit our bodies in a myriad of ways. Artistic skills reside in more than just the mind - they are not just a matter of "how-to". Artistic skills dwell within the hands, the eyes, and indeed in one's whole being. This is true for many of the arts - the way a musician's ears and fingers guide him; the manner in which a dancer's limbs sense the next move; an actor's memorized lines, her sense of space and gesture, and the energy between herself and the other actors. It is a kind of knowledge located within the body. As viewers and listeners, our responses are also sensed and felt, as well as thought. A writer's (and

\footnotetext{
${ }^{8}$ Matisse, H. "Notes of a Painter" (1908) in Chipp, H. B. Theories of Modern Art (Berkley and Los Angeles: University of California Press, 1968) p. 135.

9 Cohen, T \& Guyer, P. "Introduction," in Essays in Kant's Aesthetics, Cohen, T \& Guyer, P, eds. (Chicago: University of Chicago Press, 1982).
} 
reader's) imagination comes through what is felt bodily - a sense of place, the presence and emotional state of a character. In the realm of education, I feel it is important to retain the bodily grounding afforded us by traditional media, and to aim for familiarity with the foundations of various art forms.

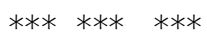

Now I would like to look at other aspects in more detail that encourage authentic learning through the arts, such as: connecting with the emotions, making sense of one's experience and the student-teacher relationship. As engagement and practice in the arts connect us with our corporeal selves, they bring us closer to what is felt within. There are not many areas elsewhere in a curriculum where this is normally done. Human emotion is what the arts have always dealt with - they have been "containers for, and moulders of, feeling," as Ellen Dissanayake says. Not only do we sense and recognize in other works of art the emotions we may ourselves have experienced, or seen in the lives of others, one's own process of making art provides a channel where some of our feelings can go. Indeed, this is what we mean by expression. When we talk about knowing ourselves, it is primarily the exploration and validation of our emotions to which we refer - our affiliations, inclinations, weaknesses and aversions, and all the contentment and conflict therein.

Art can also provide students with a way to make sense of their experiences, and to record those experiences through aesthetic means. Through his vivid abstract paintings, artist Howard Hodgkin recalls particular incidences the way a poet might. To him they record and bring to light certain "emotional situations" that he has lived through - a particular afternoon in summer, a visit to a certain city, a conversation with someone. ${ }^{10}$ In the same way, the execution of a painting, sculpture, or other artistic work can enable a student to render a particular experience, or set of experiences, as more meaningful and memorable. In many respects, engagement in art brings about a kind of understanding, a wordless cognition, a way of attending to what is around and within us that is not often possible through other means.

For both teacher and student, art education causes us to examine and explore our individual beliefs and aesthetic inclinations, and to consider the cultural and aesthetic influences of the world around us - some of which we may wish to take in, others from which we may want to turn away. The source of the word 'belief' is from the Anglo-Saxon word geliefan, which means, "to hold dear."11 Validation of inner knowledge, affections, and inclinations is part of the practice of art, and also the teaching of art. The choices that are made along the way are personal and affecting. One satisfies one's own ideas and aesthetic sensibility while learning about other preferences of viewing and working. Choosing what feels right for oneself in the face of myriad other influences is an important practice in life, both in terms of living well within a community, as well as in a society often characterized by media and advertising. It is important to remember that art is most meaningful when it is something "in here", as opposed to something "out there" on a frontier, or in an inaccessible realm.

The student-teacher relationship in the arts often takes on a special quality, one of careful balance. While the teacher needs to be active in terms of guidance through the learning of skills, history, and offering ideas and means of application, he or she has to allow the student to take from that what is most fitting for that student individually, and at times the teacher has to step back altogether. Teachers cannot help but have their own biases and preferences in terms of aesthetic sensibilities and realms of artistic knowledge. Thereby, who one is becomes very much a part of teaching, in much the same way that who one is becomes a part of their created work. Like in most realms of education, growth and learning can occur on both sides of the student-teacher relationship. There is a kind of multi-layered creativity that goes on, as the teacher communicates with the student as well as with, and through, the art that is in progress.

Engagement in the arts offers us ways to understand ourselves better, and also to understand others better. We become aware of other ways of seeing and being, other palpable truths, through the artistic work of others. We also come to know our companions better by talking about what we see in a work, and by making attempts to view it also in the way in which they do. Some of our most stimulating conversations with friends are often about films, books, or other works of art that we have experienced in common. In his

\footnotetext{
10 Sontag, S. 'About Hodgkin' in Where the Stress Falls (New York, Picador, 2001) p. 156.

${ }^{11}$ Levi-Strauss, D. Between the Eyes: Essays on Photography and Politics (New York: Aperture Foundation, 2003) p. 73.
} 
exploration of expression in the arts, Colin Lyas writes about the need to make something clear. ${ }^{12}$ This need guides an artist through the uncharted and often indirect process of finding the right way to a hopefully satisfying outcome. The process leads us to a kind of familiarity and connection with our own inner workings in ways that we cannot always understand, but that we nevertheless trust are real. And in resonating with a work of art, or in making efforts to understand the perceptions of others, we also work toward a clarity that brings us closer to our fellow human beings.

Perhaps the most notable characteristic of an authentic life is that we learn to follow our hearts and better inclinations as well as our own values. Aesthetic education and involvement in the arts provide many avenues to feed and explore what it is we hold dear: we validate our beliefs and satisfy our ideas while remaining open to new areas of thought and perception. In education, the arts can go a long way toward encouraging students to be true to themselves while respecting and being curious about the ways of others. By calling upon imagination, emotion, and embodied practice, the arts enable us to connect with ourselves and with the greater culture. The influences of the commercial media and of instrumentalism often lead us to mistrust the value of our own experience and to distance us from our senses, manipulating our emotions and steering us away, in many respects, from a sense of our own authenticity. Involvement in the arts is one way to lead us back to it.

\section{Acknowledgments}

I would like to express my gratitude to Dr. Stuart Richmond, with whom I presented this work at the Education With/Out Borders symposium. While the points raised herein elaborate mostly on my part of the presentation, Dr. Richmond provided much of the initial framework, which we then worked on together, interweaving our ideas. I have acknowledged where the ideas are directly his, and would like to acknowledge my indebtedness to him as a teacher.

\section{References}

Cohen, T \& Guyer, P. "Introduction," in Essays in Kant's Aesthetics, Cohen, T \& Guyer, P, eds. (Chicago: University of Chicago Press, 1982).

Csikszentmihalyi, M. Finding Flow: The Psychology of Engagement with Everyday Life (New York: Harper Collins, 1997).

Eagleton, T. After Theory (London: Penguin, 2003).

Kant, I. The Critique of Judgement, J.C. Meridith, trans. (Oxford: Clarendon Press, 1982).

Levi-Strauss, D. Between the Eyes: Essays on Photography and Politics (New York: Aperture Foundation, 2003).

Lyas, C. Aesthetics (Montreal: McGill-Queen's University Press, 2000).

Matisse, H. "Notes of a Painter" (1908) in Chipp, H. B. Theories of Modern Art (Berkley and Los Angeles: University of California Press, 1968) p. 135.

Murdoch, I. The Sovereignty of Good (London: Routledge and Kegan Paul, 1971).

Sontag, S. 'About Hodgkin' in Where the Stress Falls (New York, Picador, 2001) p. 156.

Taylor, C. The Malaise of Modernity (Toronto: House of Anansi Press, 2003).

\section{About the Author}

Zuzana Vasko is a doctoral student focusing on Arts Education in the Faculty of Education at Simon Fraser University. Her interests include the visual arts, writing, and aesthetic education (zvasko@,telus.net).

\footnotetext{
${ }^{12}$ Lyas, C. Aesthetics (Montreal: McGill-Queen's University Press, 2000) chapters 5, 10.
} 